\title{
The importance of polarizability: Comparison of models of carbon disulphide in the ionic liquids $\left[\mathrm{C}_{1} \mathrm{C}_{1} \mathrm{im}\right]\left[\mathrm{NTf}_{2}\right]$ and $\left[\mathrm{C}_{4} \mathrm{C}_{1} \mathrm{im}\right]\left[\mathrm{NTf}_{2}\right]$
}

\author{
Ruth M.Lynden-Bell, ${ }^{* a}$ and Edward L. Quitevis, ${ }^{b}$ \\ Received Xth $X X X X X X X X X X 20 X X$, Accepted Xth $X X X X X X X X X 20 X X$ \\ First published on the web Xth $X X X X X X X X X X 200 X$ \\ DOI: 10.1039/b000000x
}

The local environment of $\mathrm{CS}_{2}$ and in solution in two ionic liquids $\left(\left[\mathrm{C}_{1} \mathrm{C}_{1}\right.\right.$ im $]\left[\mathrm{NTf}_{2}\right]$ and $\left[\mathrm{C}_{4} \mathrm{C}_{1}\right.$ im $\left.]\left[\mathrm{NTf}_{2}\right]\right)$ are investigated by atomistic simulation and compared with that in neat $\mathrm{CS}_{2}$. The intermolecular vibrational densities of states of $\mathrm{CS}_{2}$ are calculated and compared with experimental OHD-RIKES spectra. The fair agreement of the results from solutions but poor agreement of the results from neat $\mathrm{CS}_{2}$ suggest that while collective effects are unimportant in solutions, they have a major effect on the OHD-RIKES spectrum of neat $\mathrm{CS}_{2}$. Comparing polarizable and unpolarizable models for $\mathrm{CS}_{2}$ emphasizes the importance of polarizability in determining local structure.

\section{Introduction}

The solvation mechanism of molecular solutes in ionic liquids (ILs) can be quite different than in conventional molecular solvents not only because of the ionicity of ILs $^{1}$ but also because of their nanoscale structural heterogeneity. That such heterogeneity is present in ILs was first evidenced by molecular dynamics (MD) simulations of ILs based on 1alkyl-3-methylimidazolium $\left(\left[\mathrm{C}_{n} \mathrm{C}_{1} \mathrm{im}\right]^{+}\right)^{2-4}$ and experimentally by small-wide $\mathrm{X}$-ray scattering (SWAXS) measurements on $\left[\mathrm{C}_{n} \mathrm{C}_{1} \mathrm{im}\right][\mathrm{Cl}]$ and $\left[\mathrm{C}_{n} \mathrm{C}_{1} \mathrm{im}\right]\left[\mathrm{BF}_{4}\right] .{ }^{5}$ Initially, the existence of heterogeneity in ILs was met with scepticism, particularly in the assignment of the prepeak in the total scattering function $\mathrm{S}(\mathrm{q})$ to nanoscale correlations associated with this heterogeneity. ${ }^{6}$ However, these doubts have largely been laid to rest by Margulis and coworkers ${ }^{7}$ who through the use of MD simulations showed how $\mathrm{S}(\mathrm{q})$ can be resolved into components corresponding to correlations between the types of charge-density regions reflecting this heterogeneity.

The heterogeneity in ILs is characterized by nonpolar domains (low-charge density regions) embedded or intertwined with polar domains (high-charge density regions) that arise from the nanosegregation of the alkyl tails, with the degree of structural heterogeneity being dictated by the length of the $\mathrm{C}_{n}$-alkyl tails. Recent $\mathrm{MD}$ simulations on the $\left[\mathrm{C}_{n} \mathrm{C}_{1} \mathrm{im}\right]\left[\mathrm{NTf}_{2}\right]$ series of ILs, where $\left[\mathrm{NTf}_{2}\right]^{-}$is the bis[(trifluoromethane)sulfonyl]amide anion, reveal a more complex picture of the evolution of the morphology with increasing alkyl chain length from isolated 'hydrocarbonlike islands in the midst of a continuous polar network' for

${ }^{a}$ Department of Chemistry, University of Cambridge, Cambridge CB2 1EW, UK.E-mail:rmlb@cam.ac.uk

${ }^{b}$ Department of Chemistry and Biochemistry, Texas Tech University, Lubbock, TX 79409, USA. edward.quitevis@ttu.edu short chains $(n=2-4)$ that percolate to form a continuous nonpolar microphase for longer alkyl chains with the percolation threshold occurring at $n=6 .{ }^{8}$ Given this scenario of polar and nonpolar domains, the modes of solvation of molecular solutes can be understood from the chemical adage 'like dissolves like' with nonpolar solutes residing in the low-charge density regions, polar protic solutes in the high-charge density regions, and polar aprotic solutes at the interface between the high-charge and lowcharge density regions, as shown, respectively, in simulations of mixtures of hexane/[ $\left.\mathrm{C}_{6} \mathrm{C}_{1} \mathrm{im}\right]\left[\mathrm{PF}_{6}\right], \mathrm{H}_{2} \mathrm{O} /\left[\mathrm{C}_{6} \mathrm{C}_{1} \mathrm{im}\right]\left[\mathrm{PF}_{6}\right]$, and $\mathrm{CH}_{3} \mathrm{CN} /\left[\mathrm{C}_{6} \mathrm{C}_{1} \mathrm{im}\right]\left[\mathrm{PF}_{6}\right]{ }^{9,10}$ Recent experimental measurements of butane and isobutane in imidazolium-based ILs backed by MD simulations, provide further support for nonpolar aprotic alkane solutes being localized in the low-charge density regions of the IL. ${ }^{11,12}$ Nonpolar aromatic solutes, such as benzene, are a special case because of their propensity to interact with the imidazolium ring through local electrostatic interactions giving rise to $\pi$-stacking. ${ }^{13-17}$

In a recent study, Xue et al. ${ }^{18}$ found that mixtures of certain nonpolar aprotic solutes and $\left[\mathrm{C}_{1} \mathrm{C}_{1} \mathrm{im}\right]\left[\mathrm{NTf}_{2}\right]$ appear to be at odds with the paradigm of nonpolar solutes residing mainly in the low-charge density regions. Because $\left[\mathrm{C}_{1} \mathrm{C}_{1}\right.$ im $]\left[\mathrm{NTf}_{2}\right]$ lacks the long $\mathrm{C}_{n}$ chain $(\mathrm{n}>2)$ required to form nonpolar domains, the solubility of a nonpolar aprotic solute must solely be determined by its interaction with the high-charge density part of $\left[\mathrm{C}_{1} \mathrm{C}_{1} \mathrm{im}\right]\left[\mathrm{NTf}_{2}\right]$. They found that upon mixing, a $10 \mathrm{~mol} \%$ mixture of $\mathrm{CCl}_{4}$ and $\left[\mathrm{C}_{1} \mathrm{C}_{1} \mathrm{im}\right]\left[\mathrm{NTf}_{2}\right]$ formed an optically clear solution, whereas a 10 mol\% mixture of $n-$ pentane and $\left[\mathrm{C}_{1} \mathrm{C}_{1} \mathrm{im}\right]\left[\mathrm{NTf}_{2}\right]$ formed a cloudy emulsion. Similar results were obtained for the $20 \mathrm{~mol} \%$ mixtures of $\mathrm{CCl}_{4}$ and $\left[\mathrm{C}_{1} \mathrm{C}_{1} \mathrm{im}\right]\left[\mathrm{NTf}_{2}\right]$ and n-pentane and $\left[\mathrm{C}_{1} \mathrm{C}_{1} \mathrm{im}\right]\left[\mathrm{NTf}_{2}\right]$. In contrast, a $10 \mathrm{~mol} \%$ mixture of $\mathrm{CS}_{2}$ and $\left[\mathrm{C}_{1} \mathrm{C}_{1} \mathrm{im}\right]\left[\mathrm{NTf}_{2}\right]$ formed an optically clear solution, whereas a $20 \mathrm{~mol} \% \mathrm{mix}-$ 
ture of $\mathrm{CS}_{2}$ and $\left[\mathrm{C}_{1} \mathrm{C}_{1} \mathrm{im}\right]\left[\mathrm{NTf}_{2}\right]$ formed a cloudy emulsion. These tests showed the relative solubilities in $\left[\mathrm{C}_{1} \mathrm{C}_{1}\right.$ im $]\left[\mathrm{NTf}_{2}\right]$ at room temperature to be in the order n-pentane $<\mathrm{CS}_{2}<$ $\mathrm{CCl}_{4}$. As $\mathrm{CS}_{2}$ is polarizable it can interact with the highcharge density regions of the IL via charge-induced dipole forces. Therefore, the greater the molecular polarizability of the solute, the greater is its solubility in $\left[\mathrm{C}_{1} \mathrm{C}_{1} \mathrm{im}\right]\left[\mathrm{NTf}_{2}\right]$. Given that the mean molecular polarizability of $\mathrm{CCl}_{4}(11.7 \times$ $\left.10^{-40} \mathrm{~J} \mathrm{~V}^{-2} \mathrm{~m}^{2}\right)^{19}$ is greater than that of $\mathrm{CS}_{2}\left(9.7 \times 10^{-40} \mathrm{~J}\right.$ $\left.\mathrm{V}^{-2} \mathrm{~m}^{2}\right),{ }^{19}$ this correlation between polarizability and solubility is consistent with solubility of $\mathrm{CCl}_{4}$ in $\left[\mathrm{C}_{1} \mathrm{C}_{1} \mathrm{im}\right]\left[\mathrm{NTf}_{2}\right]$ being greater than that of $\mathrm{CS}_{2}$. Because the molecular polarizability of n-pentane $\left(11.1 \times 10^{-40} \mathrm{~J} \mathrm{~V}^{-2} \mathrm{~m}^{2}\right)^{19}$ is almost equal to that of $\mathrm{CCl}_{4}$, one would have predicted that the solubilities of n-pentane and $\mathrm{CCl}_{4}$ should be the same, and that n-pentane should have a greater solubility than $\mathrm{CS}_{2}$, which is contrary to the results of the solubility tests. Because solvation in the high-charge density regions of the IL involves disruption of the charge-order, the size of the solute must also be considered in that small solutes would be more readily accommodated in the charge-ordered network than large solutes. This would explain the relative observed solubilities of $\mathrm{CCl}_{4}$ and n-pentane, even though they have nearly the same polarizabilities. As the molecular volume of n-pentane $\left(V_{\mathrm{vdW}}=107 \AA^{3}\right)$ is larger than $\left.\mathrm{CCl}_{4}\left(V_{\mathrm{vdW}}=88.3 \AA^{3}\right)\right)$ and $\left.\mathrm{CS}_{2}\left(V_{\mathrm{vdW}}=55.6 \AA^{3}\right)\right)$, we would predict that the solubility of n-pentane to be less than that of $\mathrm{CS}_{2}$ and $\mathrm{CCl}_{4}$, in agreement with the solubility tests. However, using solute size alone, we would also predict that the solubility of $\mathrm{CS}_{2}$ should be greater than that of $\mathrm{CCl}_{4}$, contrary to the solubility tests. Therefore, in the solvation of nonpolar, nonaromatic solutes in $\left[\mathrm{C}_{1} \mathrm{C}_{1} \mathrm{im}\right]\left[\mathrm{NTf}_{2}\right]$, the polarizability of a solute appears to play a greater role than its molecular size.

$\mathrm{CS}_{2}$ is often used as a reference in OHD-RIKES spectroscopy as its large anisotropic polarizability gives a strong signal. ${ }^{20-24}$ Xue et al. ${ }^{18}$ have made measurements of the Kerr spectra of solutions of $\mathrm{CS}_{2}$ in $\left[\mathrm{C}_{n} \mathrm{C}_{1} \mathrm{im}\right]\left[\mathrm{NTf}_{2}\right]$. In order to model these systems in computer simulations one needs a model for the interaction of $\mathrm{CS}_{2}$ with the other species present.

We wondered whether it was important to include the polarizability of $\mathrm{CS}_{2}$ in the simulation or whether properties of the mixture would be described adequately by a non-polarizable model. To investigate this we have compared simulations of $\mathrm{CS}_{2}$ in $\left[\mathrm{C}_{1} \mathrm{C}_{1} \mathrm{im}\right]\left[\mathrm{NTf}_{2}\right]$ and $\left[\mathrm{C}_{4} \mathrm{C}_{1} \mathrm{im}\right]\left[\mathrm{NTf}_{2}\right]$ using different models of $\mathrm{CS}_{2}$. We find that while the properties of solutions of $\mathrm{CS}_{2}$ in the ionic liquid are much the same for models with and without charges, including polarizability affects the local structure considerably. We find considerable differences between the imidazolium ionic liquid with a butyl side chain and one with a methyl side chain which we attribute to the presence and absence of non-polar domains in the liquid. Of course the $\mathrm{S}$ atoms of $\mathrm{CS}_{2}$ are not the only polarizable atoms in the system, but with the computational resources available to us it is not practical to make all the atoms polarizable. Kerr spectra of solutions of solutions of $\mathrm{CS}_{2}{ }^{18,20-24}$ show that the dominant contribution comes from the anisotropically polarizable $\mathrm{CS}_{2}$. Hence in this current work we only include the polarizability of $\mathrm{CS}_{2}$.

\section{Models and simulation conditions.}

$\mathrm{CS}_{2}$ has been modelled in computer simulations for many years. Tildesley and Madden ${ }^{25}$ first introduced a model with three Lennard-Jones sites on a rigid $\mathrm{CS}_{2}$ molecule which gave good liquid properties. This is our first model, the T\&M model. However the molecule has a quadrupole moment ${ }^{26}$ and our second model, the charged model, has charged sites in addition to the Lennard-Jones terms. The charges are taken from Torii ${ }^{27}$ which were chosen to fit the electrostatic field around a molecule. Although Torii showed that one needs site quadrupoles in addition to site charges to obtain a good fit to the electrostatic field of the molecule, we have not included such terms. Our third model includes polarizability - the polarizable model. Polarizability was modelled using the shell model with shells on the two sulphur sites, but with no interactions between sites in the same molecule. This model does not account for the difference in molecular polarizability parallel and perpendicular to the symmetry axis, but does allow the molecule to respond to an unsymmetric environment. The polarisability of $\mathrm{CS}_{2}$ has been measured ${ }^{28,29}$ and calculated ${ }^{30}$ to be approximately $14 \AA^{3}$ parallel and $5.5 \AA^{3}$ perpendicular to the molecular axis. The force constant for the harmonic coreshell interaction was chosen to give an atomic polarizability volume, $\alpha_{S}$ of $7 \AA^{3}$ by setting it to $2431 \mathrm{~kJ} / \AA^{2}$. The mass of each shell was set equal to $0.5 \mathrm{amu}$ with a corresponding reduction of the mass of the core. The charge of each sulfur atom is divided to give a charge of $-3.5 \mathrm{e}$ on the shell and $+3.618 \mathrm{e}$ on the core. Additional runs with a model with half the polarizability were carried out, the halfpol model. Again no intramolecular polarization was allowed. Simulations of neat $\mathrm{CS}_{2}$ showed that the Lennard-Jones $\sigma$ parameters had to be increased in the polarizable model to obtain a pressure near 1 atmosphere. The values used for the $\mathrm{C}$ and $\mathrm{S}$ potential parameters are shown in Table 1.

The models for the $\left[\mathrm{C}_{1} \mathrm{C}_{1} \mathrm{im}\right]^{+}$and $\left[\mathrm{C}_{4} \mathrm{C}_{1} \text { im }\right]^{+}$were taken from the work of Canongia Lopes and Pádua ${ }^{31}$ while that for $\left[\mathrm{NTf}_{2}\right]^{-}$was taken from Köddermann et al. ${ }^{32}$. Note that while the cation potential is an all-atom potential, the anion potential is a 9-site potential with united $\mathrm{CF}_{3}$ groups. In all cases the Lennard-Jones cross terms were calculated using LorentzBerthelot combining rules. ${ }^{33}$

Molecular dynamics simulations were performed with a modified version of the program DL_POLY ${ }^{34}$ using the dynamic shell model. Runs were performed with time steps of $2 \mathrm{fs}$ for the unpolarized models and $0.5 \mathrm{fs}$ for the polariz- 
able models. Several independent runs were carried out in the NVT ensemble at $300 \mathrm{~K}$ with a Nose Hoover thermostat with time constant $=0.5 \mathrm{ps}$. The electrostatics was calculated using an Ewald sum with precision $10^{-5}$. This corresponds to the Ewald parameters $\alpha=2.2470 \times 10^{-1} \AA^{-1}$ and a maximum $\mathrm{k}$ vector equal to $\left(\begin{array}{l}8 \\ 8\end{array} 8\right)$. The stability of the Ewald sum was checked by monitoring the Coulomb energy and Coulomb virial, which remained constant and equal and opposite within the required precision. The real space cutoff for both the Ewald and the Lennard-Jones terms was chosen to be $1.25 \mathrm{~nm}$. Some runs were made at $400 \mathrm{~K}$ where the molecular structure equilibrates more rapidly to check that the systems were equilibrated. The periodically repeated cubic cell with dimensions $37.0 \AA^{3}$ contained 124 ion pairs and $8 \mathrm{CS}_{2}$ molecules, that is a molar percentage of $6 \%$. Note the maximum solubility recently measured in our laboratory is $13 \%$.

Table 1 Potential parameters for $\mathrm{C}$ and $\mathrm{S}$ sites in $\mathrm{CS}_{2}$ in the four models. The values for the Lennard-Jones $\varepsilon_{i i}$ are in $\mathrm{kJ} / \mathrm{mol}$, for $\sigma_{i i}$ are in nm and the polarizability volume $\alpha_{S}$ is in $\AA^{3}$.

\begin{tabular}{lllllll}
\hline & $\varepsilon_{\mathrm{CC}}$ & $\sigma_{\mathrm{CC}}$ & $q_{C} / \mathrm{e}$ & $\varepsilon_{\mathrm{SS}}$ & $\sigma_{\mathrm{SS}}$ & $\alpha_{S}$ \\
\hline T\&M & 0.4257 & 0.335 & 0. & 1.521 & 0.352 & 0. \\
charged & 0.4257 & 0.335 & -0.236 & 1.521 & 0.352 & 0. \\
polarizable & 0.4257 & 0.33853 & -0.236 & 1.521 & 0.3552 & 7.0 \\
halfpol & 0.4257 & 0.33853 & -0.236 & 1.521 & 0.3552 & 3.6 \\
\hline
\end{tabular}

\section{Energetics}

We can compare the energetics of the interaction of a $\mathrm{CS}_{2}$ molecule with the two ionic liquids for the different models. This shows both the effects of including polarizability and the difference due to the side chain.

The data in Table 2 show that the Lennard-Jones energy of $\mathrm{CS}_{2}$ in $\left[\mathrm{C}_{1} \mathrm{C}_{1} \mathrm{im}\right]\left[\mathrm{NTf}_{2}\right]$ is almost the same for all the models. This term dominates the energy in the charged model and the half polarizable model, and even in the fully polarizable model it is comparable to the electrostatic energy. One must also include the cost of polarizing the molecules in the total energy, which is given in the table. The errors were calculated from the variation between different runs. It is noteworthy that the electrostatic interactions are much more negative and the polarization energies are higher in solutions in either of these ionic liquids than in a simulation of a pure liquid of the fully polarizable model of $\mathrm{CS}_{2}$. In the neat liquid the net electrostatic energy (Coulomb plus polarization) is only $-0.7 \mathrm{~kJ} / \mathrm{mol}$ in contrast to $-24.3 \mathrm{~kJ} / \mathrm{mol}$ in the ionic liquid environment. Increasing the temperature of $\left[\mathrm{C}_{1} \mathrm{C}_{1} \mathrm{im}\right]\left[\mathrm{NTf}_{2}\right]$ from $300 \mathrm{~K}$ to $400 \mathrm{~K}$ results in the total interaction energies becoming less negative by about $2 \mathrm{~kJ} / \mathrm{mol}$.

There is an interesting difference between the $\left[\mathrm{C}_{1} \mathrm{C}_{1} \mathrm{im}\right]^{+}$
Table 2 Contributions ${ }^{(a)}$ to the interaction energy of $\mathrm{CS}_{2}$ with surroundings (in $\mathrm{kJ} / \mathrm{mol}$ per $\mathrm{CS}_{2}$ molecule)

\begin{tabular}{|c|c|c|c|c|}
\hline & $\mathrm{T} \& \mathrm{M}$ & charged & halfpol & polarizable \\
\hline \multicolumn{5}{|c|}{$\left[\mathrm{C}_{1} \mathrm{C}_{1} \mathrm{im}\right]\left[\mathrm{NTf}_{2}\right]$} \\
\hline ES & 0 & $-2.32 \pm 0.1$ & $-11.0 \pm 0.3$ & $-52.6 \pm 2.0$ \\
\hline $\mathrm{LJ}$ & $-35.2 \pm 0.2$ & $-35.7 \pm 0.2$ & $-36.2 \pm 0.2$ & $-34.7 \pm 0.2$ \\
\hline Epol & 0 & 0 & $+3.9 \pm 0.1$ & $+23.8 \pm 0.8$ \\
\hline total & $-35.2 \pm 0.2$ & $-38.0 \pm 0.2$ & $-43.3 \pm 0.4$ & $-63 \pm 2$ \\
\hline \multicolumn{5}{|c|}{$\left[\mathrm{C}_{4} \mathrm{C}_{1} \mathrm{im}\right]\left[\mathrm{NTf}_{2}\right]$} \\
\hline ES & & $-1.82 \pm 0.03$ & & $-23.4 \pm 0.6$ \\
\hline $\mathrm{LJ}$ & & $-37.6 \pm 0.2$ & & $-39.2 \pm 0.1$ \\
\hline Epol & & 0 & & $+14.9 \pm 0.4$ \\
\hline total & & $-39.5 \pm 0.2$ & & $-47.6 \pm 0.2$ \\
\hline \multicolumn{5}{|c|}{$\mathrm{CS}_{2}$ (neat) } \\
\hline ES & 0 & -0.11 & & $-1.97 \pm .01$ \\
\hline $\mathrm{LJ}$ & -24.5 & -24.5 & & $-25.1 \pm .01$ \\
\hline Epol & 0 & 0 & & $1.24 \pm .01$ \\
\hline total & -24.5 & -24.6 & & $-25.8 \pm .01$ \\
\hline
\end{tabular}

${ }^{(a)}$ ES:Coulomb; LJ:Lennard-Jones; Epol: energy of polarization

and $\left[\mathrm{C}_{4} \mathrm{C}_{1} \mathrm{im}\right]^{+}$cations. While the Lennard-Jones energy in the $\left[\mathrm{C}_{4} \mathrm{C}_{1} \mathrm{im}\right]\left[\mathrm{NTf}_{2}\right]$ ionic liquid is more negative by about $4 \mathrm{~kJ} / \mathrm{mol}$ than in the $\left[\mathrm{C}_{1} \mathrm{C}_{1} \mathrm{im}\right]\left[\mathrm{NTf}_{2}\right]$ liquid, the electrostatic energy of the polarizable model in $\left[\mathrm{C}_{4} \mathrm{C}_{1} \mathrm{im}\right]\left[\mathrm{NTf}_{2}\right]$ is about half the value as it is in $\left[\mathrm{C}_{1} \mathrm{C}_{1} \mathrm{im}\right]\left[\mathrm{NTf}_{2}\right]$. This is the result of changes in the local environment of the $\mathrm{CS}_{2}$ molecule. In $\left[\mathrm{C}_{4} \mathrm{C}_{1} \mathrm{im}\right]\left[\mathrm{NTf}_{2}\right]$ the $\mathrm{CS}_{2}$ has a high probability of being in the non-polar domains near the cation tails rather than near the charged domains near the rings. In $\left[\mathrm{C}_{1} \mathrm{C}_{1} \mathrm{im}\right]\left[\mathrm{NTf}_{2}\right]$, however, the cation side chains are too short to form non-polar domains and the $\mathrm{CS}_{2}$ interacts more strongly with the charged ring.

\section{Local environment}

\subsection{Radial distribution functions}

Radial distribution functions were calculated for a number of cation and anion sites relative to $\mathrm{C}$ and $\mathrm{S}$ sites on the $\mathrm{CS}_{2}$ molecules. These show rather little change for anion sites, but a dramatic change for cation sites.

Figure 1 shows radial distribution functions between the ring carbon atoms in both $\left[\mathrm{C}_{1} \mathrm{C}_{1} \mathrm{im}\right]^{+}$and $\left[\mathrm{C}_{4} \mathrm{C}_{1} \mathrm{im}\right]^{+}$and the centre of the $\mathrm{CS}_{2}$ molecule for various models. In $\left[\mathrm{C}_{1} \mathrm{C}_{1} \mathrm{im}\right]\left[\mathrm{NTf}_{2}\right]$ there is a big change in the radial distribution function for $\mathrm{C}_{2}$, the unique carbon atom on the $\left[\mathrm{C}_{1} \mathrm{C}_{1} \mathrm{im}\right]^{+}$ ring. As polarization is added the $\mathrm{CS}_{2}$ molecule is attracted to this atom and its probability density becomes more localised. The distributions relative to the adjacent carbon atoms in the ring, $\mathrm{C}_{4}$ and $\mathrm{C}_{5}$, also show a similar, but less pronounced, effect. On the other hand in $\left[\mathrm{C}_{4} \mathrm{C}_{1} \mathrm{im}\right]\left[\mathrm{NTf}_{2}\right]$ there is much less change on adding polarisability. This can be attributed to the attraction of the $\mathrm{CS}_{2}$ molecules to the butyl side chain. Figure 
2 demonstrates that the distance of closest approach of $\mathrm{CS}_{2}$ to the anion is longer than to the cation. The various models give essentially the same radial distributions relative to the central $\mathrm{N}$ site of $\left[\mathrm{NTf}_{2}\right]\left(=\left[\mathrm{N}\left(\mathrm{SO}_{2} \mathrm{CF}_{3}\right)_{2}\right]^{-}\right)$and rather small changes to the peripheral $\mathrm{O}$ sites.

Figure 3 is interesting because it shows that in the charged model there is a strong tendency for the $\mathrm{CS}_{2}$ molecules to be near the tail, especially near to the terminal methyl group. On the other hand the tendency is less marked for the polarizable $\mathrm{CS}_{2}$ molecules.

The radial distribution functions from the $\mathrm{CS}_{2}$ molecule to the central site $(\mathrm{N})$ and the $\mathrm{O}$ sites on the anions show that the $\mathrm{CS}_{2}$ molecules do not approach the anions as closely as the cations; the first peak is at $5 \AA$ for $\mathrm{O}$ and $7 \AA$ for $\mathrm{N}$. There is little difference between the models. In summary, $\mathrm{CS}_{2}$ molecules tend to be closer to the cations than to the anions particularly in the polarizable model. The distributions are also more structured in the latter.

Values for the number of nearest neighbours for the central $\mathrm{C}$ of $\mathrm{CS}_{2}$ can be calculated from these radial distribution functions. There are on average about 0.6 cations in the sharp first peak of the polarizable model (to $4.1 \AA$ ), which is considerably larger than for the other models. Including the second peak one obtains about 3.3 neighbours, which is the same as the number to this distance for the other models. This shows that, in this model, some cations from the first shell of neighbours are pulled close to the $\mathrm{CS}_{2}$ molecule.

\subsection{Spatial distribution functions}

More insight into these changes can be found by looking at the spatial probability distribution functions for $\mathrm{CS}_{2}$ around the cations. In Figures 4 and 5 these functions are shown for the charged models and the polarizable models of $\left[\mathrm{C}_{1} \mathrm{C}_{1} \mathrm{im}\right]\left[\mathrm{NTf}_{2}\right]$ and $\left[\mathrm{C}_{4} \mathrm{C}_{1} \mathrm{im}\right]\left[\mathrm{NTf}_{2}\right]$. First, comparing the polarizable and unpolarizable models, we see that in both liquids the distributions around the cations are much more localised in the polarizable models (red) than in the charged models (blue). Note that in both liquids the density contours used to show the distributions are 3 times the average for the polarizable models but only 1.3 times the average for the charged models. If the higher cutoff were used for the charged models nothing would be seen. There are considerable differences in the distributions around the two cations. For $\left[\mathrm{C}_{1} \mathrm{C}_{1} \text { im }\right]^{+}$polarizable $\mathrm{CS}_{2}$ tends to lie above and below the unique $\mathrm{CH}$ bond, while near $\left[\mathrm{C}_{4} \mathrm{C}_{1} \mathrm{im}\right]^{+}$polarizable $\mathrm{CS}_{2}$ tends to lie above and below the ring. The charged $\mathrm{CS}_{2}$ models have a broad band of high probability around $\left[\mathrm{C}_{4} \mathrm{C}_{1} \text { im }\right]^{+}$, but the regions of high probability for this model lie to the back of the $\left[\mathrm{C}_{1} \mathrm{C}_{1} \mathrm{im}\right]^{+}$cation near the adjacent $\mathrm{C}$ atoms.

Finally in Figure 6 we see the distributions from the point of view of a $\mathrm{CS}_{2}$ molecule. This figure shows concentrations
Table 3 First moments $\left(\mathrm{M}_{1}\right)$ and maximum frequencies $\left(v_{\max }\right)$ of density of states ${ }^{(\mathrm{a})}$ for polarizable $\mathrm{CS}_{2}$ in ionic liquid solutions and in neat $\mathrm{CS}_{2}$. Values in $\mathrm{cm}^{-1}$.

\begin{tabular}{lcllllll} 
& \multicolumn{2}{c}{$\left[\mathrm{C}_{4} \mathrm{C}_{1} \mathrm{im}\right]\left[\mathrm{NTf}_{2}\right]$} & \multicolumn{2}{c}{$\left[\mathrm{C}_{1} \mathrm{C}_{1} \mathrm{im}\right]\left[\mathrm{NTf}_{2}\right]$} & \multicolumn{2}{c}{$\mathrm{CS}_{2}$ (neat) } \\
& $\mathrm{M}_{1}$ & $v_{\max }$ & $\mathrm{M}_{1}$ & $v_{\max }$ & $\mathrm{M}_{1}$ & $v_{\max }$ \\
\hline $\mathrm{CS}_{2}$ lib & 56.1 & 40 & 67 & $45(\mathrm{~b})$ & 52 & $30(\mathrm{~b})$ \\
$\mathrm{CS}_{2}$ trans & 49.3 & $28(\mathrm{~b})$ & 57 & $26(\mathrm{~b})$ & 47 & 13 \\
\hline OKE & 35 & 21 & 36 & 24 & 44 & 28 \\
\hline
\end{tabular}

(a) (b) denotes a broad band.

of $\left[\mathrm{C}_{1} \mathrm{C}_{1} \mathrm{im}\right]^{+}$cations (above) and $\left[\mathrm{NTf}_{2}\right]^{-}$anions (below) in a plane containing a polarizable $\mathrm{CS}_{2}$ molecule. The cation positions are defined by the central point of the NN vector, while the anions are described by the positions of the four oxygen atoms. We see that the greatest concentration of cations is near the central $\mathrm{C}$ atom, while the anions tend to be near the $\mathrm{S}$ atoms where they also interact with the cations around the central $\mathrm{C}$ atom. The localisation is much less marked in the unpolarizable models (not shown).

\section{Comparison of Densities of States}

Figure 7 shows the intermolecular part of the $\mathrm{CS}_{2}$ vibrational density of states in different environments. In the neat liquid both the translational and vibrational contributions are broader and have a lower frequency than in ionic liquid solutions. There is rather little difference between the two ionic liquid solvents, but in $\left[\mathrm{C}_{4} \mathrm{C}_{1} \mathrm{im}\right]\left[\mathrm{NTf}_{2}\right]$ the response is slightly sharper with a higher maximum than in $\left[\mathrm{C}_{1} \mathrm{C}_{1}\right.$ im $]\left[\mathrm{NTf}_{2}\right]$; note that as the area under these graphs is constant the width and height are inversely correlated. In both ionic liquids the maxima in the librational and translational densities of states are blue-shifted relative to the neat liquid.

\subsection{Comparison of calculated densities of states with OKE spectra}

In the study in which the solubility tests were done, Xue et al. ${ }^{18}$ also measured the Kerr spectra of $10 \mathrm{~mol} \%$ $\mathrm{CS}_{2} /\left[\mathrm{C}_{n} \mathrm{C}_{1} \mathrm{im}\right]\left[\mathrm{NTf}_{2}\right]$ mixtures for $\mathrm{n}=1-4$ using optical heterodyne-detected Raman-induced Kerr effect spectroscopy (OHD-RIKES). The Kerr spectra of these mixtures were fitted by the sum of a $\mathrm{CS}_{2}$ component and an IL component, which was taken to be equal to the Kerr spectra of the neat IL. They found that the $\mathrm{CS}_{2}$ component was lower in frequency and narrower than the Kerr spectrum of neat $\mathrm{CS}_{2}$, in agreement with an earlier OHD-RIKES study of $\mathrm{CS}_{2} /\left[\mathrm{C}_{5} \mathrm{C}_{1}\right.$ im] $]\left[\mathrm{NTf}_{2}\right]$ mixtures. ${ }^{35-37}$ For the purposes of the comparison with densities of states calculated in the current simulation study, the $\mathrm{CS}_{2}$ contributions to the Kerr spectra of $10 \mathrm{~mol} \%$ mixtures of $\mathrm{CS}_{2}$ 
in $\left[\mathrm{C}_{1} \mathrm{C}_{1} \mathrm{im}\right]\left[\mathrm{NTf}_{2}\right]$ and $\left[\mathrm{C}_{4} \mathrm{C}_{1} \mathrm{im}\right]\left[\mathrm{NTf}_{2}\right]$ and the Kerr spectrum of neat $\mathrm{CS}_{2}$ at $295 \mathrm{~K}$ are show in Figure 8. Values of the spectral maxima, $v_{\max }$, and the first spectral moments, $\mathrm{M}_{1}$, for both simulations and observations are listed in Table 3.

As we explained in a recent article, ${ }^{16}$ densities of states by their very nature, cannot be directly compared to Kerr spectra, because densities of states are calculated from single particle velocity correlation functions (VCF), whereas Kerr spectra arise from the fluctuations in the collective polarizability anisotropy. From the perspective of instantaneous normal mode (INM) analysis one can go from a density of states to a Kerr spectrum by weighting each of modes in the density of states by the square of the derivative of the total polarizability anisotropy with respect to the canonical coordinates associated with the modes. ${ }^{38}$ In principle using a dipole-induced dipole model Kerr spectra can also be simulated. ${ }^{39-43}$ However due to the time, RAM, and disk storage required to calculate collective polarizabilities, the simulation of Kerr spectra for ILs is challenging. ${ }^{44}$ In contrast densities of states are less difficult to calculate than Kerr spectra. Indeed, in a recent study of $1: 1$ benzene/ $\left[\mathrm{C}_{1} \mathrm{C}_{1} \mathrm{im}\right]\left[\mathrm{NTf}_{2}\right]$ mixture, the densities of states were found to be consistent with the intermolecular Kerr spectra. In the current study of $\mathrm{CS}_{2} /\left[\mathrm{C}_{1} \mathrm{C}_{1} \mathrm{im}\right]\left[\mathrm{NTf}_{2}\right]$ and $\mathrm{CS}_{2} /\left[\mathrm{C}_{4} \mathrm{C}_{1} \mathrm{im}\right]\left[\mathrm{NTf}_{2}\right]$ mixtures the densities of states are only partly consistent with the intermolecular Kerr spectra.

Table 3 shows values of the first moments, $\mathrm{M}_{1}$, of the densities of states for polarizable $\mathrm{CS}_{2}$ dissolved in $\left[\mathrm{C}_{4} \mathrm{C}_{1} \mathrm{im}\right]\left[\mathrm{NTf}_{2}\right]$, in $\left[\mathrm{C}_{1} \mathrm{C}_{1} \mathrm{im}\right]\left[\mathrm{NTf}_{2}\right]$, and in neat liquid calculated from the simulations together with values of $\mathrm{M}_{1}$ obtained from OHDRIKES measurements shown in Fig.8. For simulations the values of $\mathrm{M}_{1}$ are given for the translational and librational contributions $\left(\mathrm{M}_{1}\right.$ (trans) and $\left.\mathrm{M}_{1}(\mathrm{lib})\right)$. The first moment $\mathrm{M}_{1}$ being an average over the entire spectrum provides a means of quantifying the differences between spectra with broad asymmetric line-shapes such as those obtained in simulations or OHD-RIKES measurements. From the spectral moments in Table 3, we see that the total, librational, and translational moments are higher in frequency for $\mathrm{CS}_{2}$ in $\left[\mathrm{C}_{1} \mathrm{C}_{1}\right.$ im] $]\left[\mathrm{NTf}_{2}\right]$ $\left(\mathrm{M}_{1}^{\mathrm{MD}}(\mathrm{lib})=67 \mathrm{~cm}^{-1}, \mathrm{M}_{1}^{\mathrm{MD}}(\right.$ trans $\left.)=57 \mathrm{~cm}^{-1}\right)$ than for $\mathrm{CS}_{2}$ $\left[\mathrm{C}_{4} \mathrm{C}_{1} \mathrm{im}\right]\left[\mathrm{NTf}_{2}\right]\left(\mathrm{M}_{1}^{\mathrm{MD}}(\mathrm{lib})=56 \mathrm{~cm}^{-1}, \mathrm{M}_{1}^{\mathrm{MD}}(\right.$ trans $)=49$ $\mathrm{cm}^{-1}$ ). A similar pattern is observed for values of the spectral maxima. This difference is consistent with the OHD-RIKES measurements where the intermolecular spectrum is higher in frequency for $\mathrm{CS}_{2}$ in $\left[\mathrm{C}_{1} \mathrm{C}_{1} \mathrm{im}\right]\left[\mathrm{NTf}_{2}\right]\left(\mathrm{M}_{1}^{\mathrm{OKE}}=36 \mathrm{~cm}^{-1}\right)$ than for $\mathrm{CS}_{2}$ in $\left[\mathrm{C}_{4} \mathrm{C}_{1} \mathrm{im}\right]\left[\mathrm{NTf}_{2}\right]\left(\mathrm{M}_{1}^{\mathrm{OKE}}=35 \mathrm{~cm}^{-1}\right)$. However, this difference is small and within the $1 \mathrm{~cm}^{-1}$ experimental uncertainty of the measurements. But Figure 8 clearly shows the intermolecular spectrum to be higher in frequency for $\mathrm{CS}_{2}$ in $\left[\mathrm{C}_{1} \mathrm{C}_{1} \mathrm{im}\right]\left[\mathrm{NTf}_{2}\right]$ than for $\mathrm{CS}_{2}$ in $\left[\mathrm{C}_{4} \mathrm{C}_{1} \mathrm{im}\right]\left[\mathrm{NTf}_{2}\right]$. Because the intermolecular spectra of $\mathrm{CS}_{2}$ in these ionic liquids are characterized by single bands with well-defined lineshapes, the spectral maxima are better indicators of the frequencies of the Kerr spectra than the first spectral moments. Indeed, based on the spectral maxima, the intermolecular spectrum of $\mathrm{CS}_{2}$ is slightly higher in frequency in $\left[\mathrm{C}_{1} \mathrm{C}_{1}\right.$ im] $]\left[\mathrm{NTf}_{2}\right]$ $\left(v_{\max }=24 \mathrm{~cm}^{-1}\right)$ than in $\left[\mathrm{C}_{4} \mathrm{C}_{1}\right.$ im $]\left[\mathrm{NTf}_{2}\right]\left(v_{\max }=21 \mathrm{~cm}^{-1}\right)$. Interestingly, we find that based on the first spectral moments, the librational and translational densities of states of neat $\mathrm{CS}_{2}$ are lower in frequency than those of either $\mathrm{CS}_{2}$ in $\left[\mathrm{C}_{1} \mathrm{C}_{1} \mathrm{im}\right]\left[\mathrm{NTf}_{2}\right]$ or $\mathrm{CS}_{2}$ in $\left[\mathrm{C}_{4} \mathrm{C}_{1} \mathrm{im}\right]\left[\mathrm{NTf}_{2}\right]$, which is inconsistent with the results of the OHD-RIKES measurements, where $\mathrm{M}_{1}^{\mathrm{OKE}}=44 \mathrm{~cm}^{-1}$ for neat $\mathrm{CS}_{2}$ versus $\mathrm{M}_{1}^{\mathrm{OKE}}=35 \mathrm{~cm}^{-1}$ for $\mathrm{CS}_{2}$ in $\left[\mathrm{C}_{4} \mathrm{C}_{1} \mathrm{im}\right]\left[\mathrm{NTf}_{2}\right]$ and $\mathrm{M}_{1}^{\mathrm{OKE}}=36 \mathrm{~cm}^{-1}$ for $\mathrm{CS}_{2}$ in $\left[\mathrm{C}_{1} \mathrm{C}_{1} \mathrm{im}\right]\left[\mathrm{NTf}_{2}\right]$. This discrepancy, which at first glance seems surprising, can be rationalised by remembering that a density of states is a reflection of single particle dynamics, whereas the Kerr spectrum is related to the dynamics of the collective polarizability anisotropy. Thus the difference may yield further insight into the molecular interactions in mixtures of $\mathrm{CS}_{2}$ and ILs. In the initial OHD-RIKES study of mixtures of $\mathrm{CS}_{2}$ and $\left[\mathrm{C}_{5} \mathrm{C}_{1} \mathrm{im}\right]\left[\mathrm{NTf}_{2}\right]$ by Xiao et al., ${ }^{35}$ the idea that at low concentrations $\mathrm{CS}_{2}$ molecules are isolated from each other and are localized in the nonpolar domains of the IL was based on the $\mathrm{CS}_{2}$ contribution to the Kerr spectrum of a $5 \mathrm{~mol} \%$ mixture of $\mathrm{CS}_{2}$ and $\left[\mathrm{C}_{5} \mathrm{C}_{1} \mathrm{im}\right]\left[\mathrm{NTf}_{2}\right]$ being similar to the Kerr spectrum of a $5 \mathrm{~mol} \%$ mixture of $\mathrm{CS}_{2}$ in n-pentane, with the spectrum being lower in frequency and narrower than that of neat $\mathrm{CS}_{2}$. Subsequent MD simulations of this mixture system confirmed that $\mathrm{CS}_{2}$ molecules are isolated from each other and mainly localized in the nonpolar domains. ${ }^{36} \mathrm{~A}$ red-shift and line narrowing are commonly observed in OKE spectra upon dilution of weakly interacting systems, such as $\mathrm{CS}_{2}$ in alkane mixtures. ${ }^{22,23,45-47}$ Thus we attribute the higher frequency in the OKE spectrum of the neat liquid compared with the ionic liquid solutions to increased collective interactions between $\mathrm{CS}_{2}$ molecules in the neat liquid.

The underlying mechanism for these effects is, however, controversial. ${ }^{47}$ In one mechanism the spectral changes are attributed to the softening of the effective intermolecular potential seen by $\mathrm{CS}_{2}$ molecules upon dilution. ${ }^{24,48}$ In another mechanism, the spectral changes are attributed to a decrease in interaction-induced effects upon dilution. ${ }^{46}$ In the previous studies of $\mathrm{CS}_{2} / \mathrm{IL}$ mixtures, ${ }^{18,35-37}$ the spectral changes were primarily attributed to softening of the intermolecular potential. However, the current studies suggest that these modes are not softened (see Table 3) and that the decrease in the interaction induced effects must be playing an important role in the observed spectral changes observed in $\mathrm{CS}_{2} / \mathrm{IL}$ mixtures compared with the neat liquid. For liquids comprised of anisotropic molecules, the collective polarizability anisotropy TCF can be resolved into a molecular autocorrelation, an interaction-induced (I-I) correlation, and molecularinduced cross correlation. ${ }^{49-51}$ The molecular term relaxes through single-molecule reorientation, whereas the induced 
terms (autocorrelation and cross correlation) relax through intermolecular motions. If there is a difference in the time scales of reorientational and intermolecular motions, which is the case for $\mathrm{CS}_{2},{ }^{50,51}$ the induced part of the polarizability that follows reorientation can be projected out. The result is that the TCF can then be re-expressed as the sum of a local-field modified molecular reorientation term, a collisioninduced term, and a collision-induced cross correlation, with the collision-induced terms contributing to the high-frequency part of the spectrum. Without invoking softening of the intermolecular potential, one could easily explain the red-shift and line-narrowing of the Kerr spectra as being due to the decrease in the contribution of the high-frequency collisioninduced terms upon dilution in going from the $\mathrm{CS}_{2}$ molecules in the neat liquid to $\mathrm{CS}_{2}$ molecules isolated from each other in the $\mathrm{CS}_{2} /\left[\mathrm{C}_{1} \mathrm{C}_{1} \mathrm{im}\right]\left[\mathrm{NTf}_{2}\right]$ and $\mathrm{CS}_{2} /\left[\mathrm{C}_{4} \mathrm{C}_{1} \mathrm{im}\right]\left[\mathrm{NTf}_{2}\right]$ mixtures. That the density of states of $\mathrm{CS}_{2}$ in the neat liquid is lower in frequency than that the densities of states of $\mathrm{CS}_{2}$ in the $\mathrm{CS}_{2} /\left[\mathrm{C}_{1} \mathrm{C}_{1}\right.$ im] $]\left[\mathrm{NTf}_{2}\right]$ and $\mathrm{CS}_{2} /\left[\mathrm{C}_{4} \mathrm{C}_{1}\right.$ im $]\left[\mathrm{NTf}_{2}\right]$ mixtures is not inconsistent with this explanation because the densities of states being single particle properties cannot account for collision-induced effects and in some respects would only correspond to the molecular reorientational part of the time correlation function of polarizability anisotropy. The data in Table 2 indicate that the interaction energy is greater for $\mathrm{CS}_{2}$ in the ionic liquids than in the neat liquid. This would explain why the density of states is higher in frequency for $\mathrm{CS}_{2}$ in the ionic liquids than in the neat liquid. If we assume that the molecular reorientational part of the polarizability anisotropy TCF behaves in the same way as the densities of states, then redshift and line-narrowing of the Kerr spectrum of $\mathrm{CS}_{2}$ in going from the neat liquid to the mixtures cannot be due the softening of the intermolecular potential seen by the $\mathrm{CS}_{2}$ but is due to purely a dilution effect that results in the diminished role of the collision-induced terms of the polarizability anisotropy TCF.

\section{Previous simulations}

Prior to this study, MD simulations were performed on 5, 10, and $20 \%$ mixtures of $\mathrm{CS}_{2}$ and $\left[\mathrm{C}_{5} \mathrm{C}_{1}\right.$ im] $\left[\mathrm{NTf}_{2}\right]$ and on neat $\mathrm{CS}_{2}$ and $\left[\mathrm{C}_{5} \mathrm{C}_{1} \mathrm{im}\right]\left[\mathrm{NTf}_{2}\right] .{ }^{36}$ As in the current study, the previous simulations were done in order to understand the Kerr spectra of these solutions. Briefly, the total potential energy in these simulations was described by the Amber force field with the parameters for the $\left[\mathrm{C}_{5} \mathrm{C}_{1} \mathrm{im}\right]^{+}$cation provided by the standard Amber force field and the parameters for the $\left[\mathrm{NTf}_{2}\right]^{-}$ anion from the work of Lopes and Pádua. ${ }^{52}$ For $\mathrm{CS}_{2}$ a nonpolarizable rigid-body model was used that included van der Waals and Coulombic interactions with parameters from the Amber force field. The model used in this previous study is therefore analogous to the charged model in the current study.
In the previous study the system sizes were approximately half those in the current study. For example, for the 5\% mixture, which is comparable to the $6 \%$ mixtures in the current study, the system was comprised of 72 ion pairs and four $\mathrm{CS}_{2}$ molecules. This previous study also differs from the current study in that only radial distribution functions for various sites on $\left[\mathrm{C}_{5} \mathrm{C}_{1} \mathrm{im}\right]^{+}$and $\left[\mathrm{NTf}_{2}\right]^{-}$relative to the $\mathrm{C}$ site on $\mathrm{CS}_{2}$ were calculated. Although these previous simulations were not performed with exactly the same force field as the current simulations, the results are similar with regards to the location of $\mathrm{CS}_{2}$ in the ionic liquid as reflected in the radial distribution functions. The radial distribution functions in both simulations of $\mathrm{CS}_{2}$ in $\left[\mathrm{C}_{4} \mathrm{C}_{1} \mathrm{im}\right]\left[\mathrm{NTf}_{2}\right]$ and $\mathrm{CS}_{2}$ in $\left[\mathrm{C}_{5} \mathrm{C}_{1}\right.$ im $]\left[\mathrm{NTf}_{2}\right]$ thus show $\mathrm{CS}_{2}$ molecules being closer to the terminal groups of the cation alkyl tails than to imidazolium ring or the anions, which is consistent with $\mathrm{CS}_{2}$ being mainly localized in the non-polar domains of the ionic liquids.

\section{Conclusions}

In order to model solutions of $\mathrm{CS}_{2}$ in imidazolium ionic liquids we find that it is necessary to include the polarizability of $\mathrm{CS}_{2}$; this affects both the local structure and the energetics of solvation in the highly polar environment of the ionic liquids $\left[\mathrm{C}_{1} \mathrm{C}_{1} \mathrm{im}\right]\left[\mathrm{NTf}_{2}\right]$ and $\left[\mathrm{C}_{4} \mathrm{C}_{1} \mathrm{im}\right]\left[\mathrm{NTf}_{2}\right]$. The presence of a non-polar side chain in $\left[\mathrm{C}_{4} \mathrm{C}_{1} \mathrm{im}\right]^{+}$reduces the concentration of $\mathrm{CS}_{2}$ molecules near the cation ring and increases it near the tails. However this trend is less marked when polarizability is included and electrostatic interactions increase in importance. The spectra of the densities of states of $\mathrm{CS}_{2}$ in the ionic liquids are shifted to higher frequencies than in the neat liquid, which is consistent with the increased interaction energy. In contrast, the frequency of Kerr spectrum of $\mathrm{CS}_{2}$ is lower in frequency in ionic liquid solutions than in the neat liquid. Previously, this spectral shift was attributed to a softening of the intermolecular potential. However, the simulation results for the density of states shows that the intermolecular potential of a single $\mathrm{CS}_{2}$ is harder in ionic liquid solutions than in neat liquid so that the spectral shift observed in the OKE spectrum is probably a manifestation of the diminished role of interactioninduced terms in the polarizability anisotropy time correlation function that occurs upon dilution in the ionic liquid.

\section{Acknowledgements}

Support to ELQ was provided by the National Science Foundation under Grant CHE 1153077 for the research described in this paper. 


\section{References}

1 J. E. W. Castner, J. F. Wishart and H. Shirota, Acc. Chem. Res., 2007, 40, 1217-1227.

2 S. M. Urahata and M. C. C. Ribeiro, J. Chem. Phys., 2004, 120, $1855-$ 1863.

3 Y. Wang and G. A. Voth, J. Am. Chem. Soc., 2005, 127, 12192-12193.

4 J. N. A. C. Lopes and A. A. H. Pádua, J. Phys. Chem. B, 2006, 110, 3330-3335.

5 A. Triolo, O. Russina, H.-J. Bleif and E. D. Cola, J. Phys. Chem. B, 2007, 111, 4641-4644.

6 C. Hardacre, J. D. Holbrey, C. L. Mullan, T. G. A. Youngs and D. T. Bowron, J. Chem. Phys., 2010, 133, 074510.

7 H. K. Kashyap, J. J. Hettige, H. V. R. Annapureddy and C. J. Margulis, Chem. Commun., 2012, 48, 5103-5105.

8 K. Shimizu, M. F. C. Gomes, A. A. H. Pádua, L. P. N. Rebelo and J. N. A. C. Lopes, J. Mol Struc-THEOCHEM, 2010, 946, 70-76.

9 J. N. A. C. Lopes, M. F. C. Gomes and A. A. H. Pádua, J. Phys. Chem. B, 2006, 110, 16816-16818.

10 A. A. H. Pádua, M. F. C. Gomes and J. N. A. C. Lopes, Acc. Chem. Res., 2007, 40, 1087-1096.

11 M. F. C. Gomes, L. Pison, A. S. Pensado and A. A. H. Pádua, Faraday Discuss., 2012, 154, 41-52.

12 L. Pison, K. Shimizu, G. Tama, J. N. A. C. Lopes, E. L. Quitevis and M. F. C. Gomes, Phys. Chem. Chem. Phys., 2015, 17, 30328-30342.

13 M. Deetlefs, C. Hardacre, M. Nieuwenhuyzen, O. Sheppard and A. K. Soper, J. Phys. Chem. B, 2005, 109, 1593-1598.

14 C. G. Hanke, A. Johansson, J. B. Harper and R. M. Lynden-Bell, Chem. Phys. Lett., 2003, 374, 85-90.

15 J. B. Harper and R. M. Lynden-Bell, Mol. Phys., 2004, 102, 85-94.

16 R. M. Lynden-Bell, L. Xue, G. Tamas and E. L. Quitevis, J. Chem. Phys., 2014, 141, 044506

17 L. Xue, G. Tamas, R. P. Matthews, A. J. Stone, P. A. Hunt, E. L. Quitevis and R. M. Lynden-Bell, Phys. Chem. Chem. Phys., 2015, 17, 9973-9983.

18 L. Xue, G. Tamas, E. Gurung and E. L. Quitevis, J. Chem. Phys., 2014, 140, 164512.

19 K. J. Miller, J. Am. Chem. Soc., 1990, 112, 8533-8542.

20 B. I. Greene and R. C. Farrow, Chem. Phys. Lett., 1983, 98, 273-275.

21 C. Kalpouzos, W. T. Lotshaw, D. McMorrow and G. A. Kenney-Wallace, J. Phys. Chem., 1987, 91, 2028-2030.

22 C. Kalpouzos, D. McMorrow, W. T. Lotshaw and G. A. Kenney-Wallace, Chem. Phys. Lett., 1988, 150, 138-146.

23 C. Kalpouzos, D. McMorrow, W. T. Lotshaw and G. A. Kenney-Wallace, Chem. Phys. Lett., 1989, 155, 240-242.

24 A. Scodinu and J. T. Fourkas, J. Phys. Chem. B, 2003, 107, 44-51.

25 D. Tildesley and P. Madden, Mol. Phys., 1981, 42, 1137.

26 M. Battaglia, A. D. Buckingham, D. Neumark, R. K. Pierens and J. H. Williams, Mol. Phys., 1981, 43, 1015-1020.

27 H. Torii, J. Chem. Phys., 2003, 119, 2192-2198.

28 G. R. Alms, A. K. Burnham and W.H.Flygare, J. Chem. Phys., 1975, 63, $3321-3326$.

29 M. P. Bogaard, A. D. Buckingham, R. K. Pierens and A. H. White, J. Chem. Soc.- Farad.Trans. 1, 1978, 74, 3008-3015.

30 G. Maroulis, Chem. Phys. Letts., 1992, 199, 250-256.

31 J. Canongia Lopes and A. Pádua, Theoretical Chemistry Accounts, 2012, 131, 1129.

32 T. Ködderman, D. Paschek and R. Ludwig, ChemPhysChem, 2007, 8, 2464.

33 M. Allen and D. Tildesley, Computer Simulation of Liquids;, Oxford University Press, 2nd edn, 1991.

34 W. Smith, T. Forester and I. Todorov, The DL POLY Classic User Manual, STFC Daresbury Laboratory, 2012.
35 D. Xiao, L. . G. Hines, S. Li, R. Bartsch and E. Quitevis, J. Phys. Chem. $B, 2009,113,4544-4548$.

36 P. Yang, G. A. Voth, D. Xiao, L. Hines, R. A. Bartsch and E. L. Quitevis, J. Chem. Phys., 2011, 135, 034502.

37 E. L. Quitevis, F. Bardak, D. Xiao, L. G. Hines, P. Son, R. A. Bartsch, P. Yang and G. A. Voth, Ionic Liquids: Science and Applications, 2012, pp. 271-287.

38 R. L. Murry, J. T. Fourkas and T. Keyes, J. Chem. Phys., 1998, 109, 2814 2825.

39 S. Ryu and R. M. Stratt, J. Phys. Chem. B, 2004, 108, 6782-6795.

40 B. M. Ladanyi and Y. Q. Liang, J. Chem. Phys., 1995, 103, 6325-6332.

41 G. Tao and R. M. Stratt, J. Phys. Chem. B, 2006, 110, 976-987.

42 M. D. Elola, B. M. Ladanyi, A. Scodinu, B. J. Loughnane and J. T. Fourkas, J. Phys. Chem. B, 2005, 109, 24085-24099.

43 M. D. Elola and B. M. Ladanyi, J. Phys. Chem. B, 2006, 110, 1552515541.

44 Z. Huand, X. Huang, H. V. R. Annapureddy and C. J. Margulis, J. Phys. Chem. B, 2008, 112, 7837-7849.

45 D. McMorrow, N. Thantu, J. S. Melinger, S. K. Kim and W. T. Lotshaw, J. Phys. Chem., 1996, 100, 10389-10399.

46 T. Steffen, N. A. C. M. Meinders and K. Duppen, J. Phys. Chem. A, 1998, 102, 4213-4221.

47 D. McMorrow, N. Thantu, V. Kleinman, J. S. Melinger and W. T. Lotshaw, J. Phys. Chem. A, 2001, 105, 7960-7972.

48 Q. Zhong and J. T. Fourkas, J. Phys. Chem. B, 2008, 112, 15529-15539.

49 T. Keyes, D. Kivelson and J. P. McTague, J. Chem. Phys., 1971, 55, 4096.

50 P. A. Madden and D. J. Tildesley, Mol. Phys., 1985, 55, 969-998.

51 T. I. Cox, M. R. Battaglia and P. A. Madden, Mol. Phys., 1979, 38, 15391554.

52 J. N. A. C. Lopes and A. A. H. Pádua, J. Phys. Chem. B, 2004, 108, 16893-16898. 

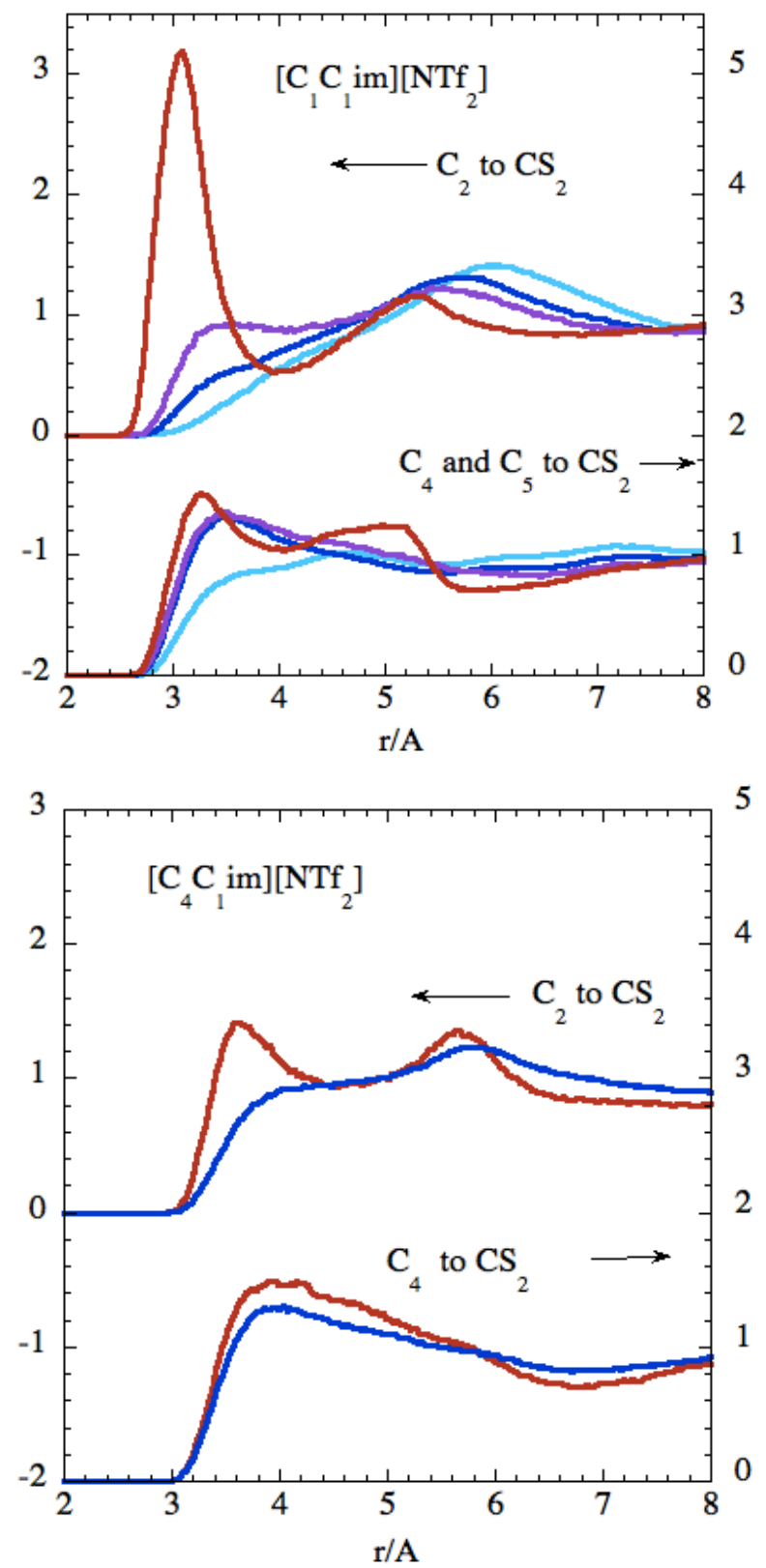

Fig. 1 Effect of polarizability on $\mathrm{g}(\mathrm{r})$ between $\mathrm{CS}_{2}$ and cation ring sites, $\mathrm{C}_{2}, \mathrm{C}_{4}$ and $\mathrm{C}_{5}$. Above: $\left[\mathrm{C}_{1} \mathrm{C}_{1}\right.$ im $]\left[\mathrm{NTf}_{2}\right]$ showing Tildesley-Madden model (cyan), charged model (blue), half-polarizable model (purple) and polarizable model (red). Below: $\left[\mathrm{C}_{4} \mathrm{C}_{1} \mathrm{im}\right]\left[\mathrm{NTf}_{2}\right]$ for the charged model (blue) and the polarizable model (red).

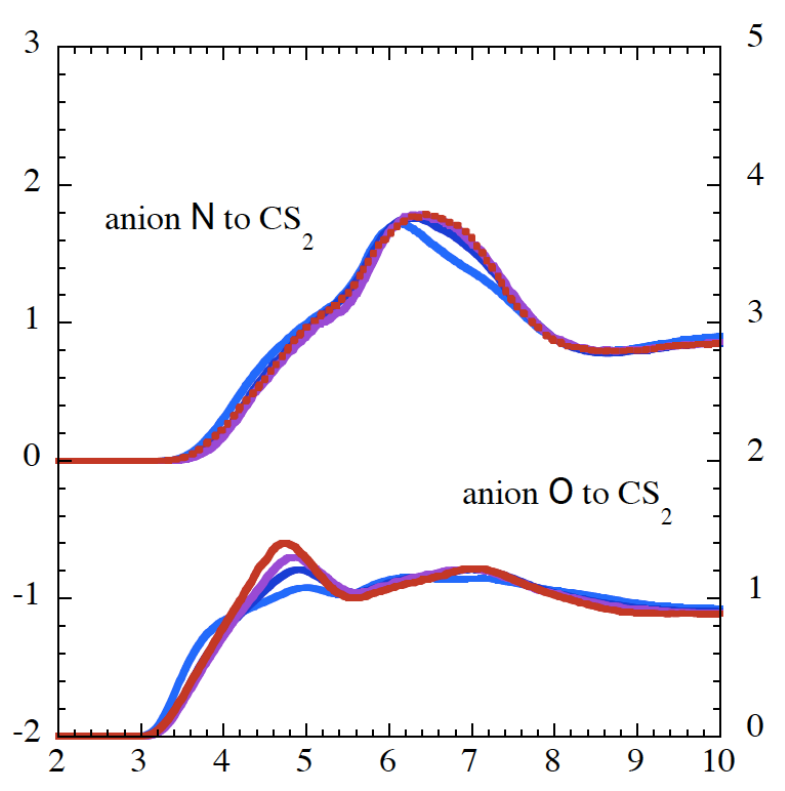

Fig. 2 Effect of polarizability on $\mathrm{g}(\mathrm{r})$ between $\mathrm{CS}_{2}$ and anion sites, $\mathrm{N}$ and $\mathrm{O}$, in $\left[\mathrm{C}_{1} \mathrm{C}_{1} \mathrm{im}\right]\left[\mathrm{NTf}_{2}\right]$ solution. Above: $\mathrm{N}$ site showing Tildesley-Madden model (blue), charged model (cyan), half-polarizable model (purple) and polarizable model (red). 

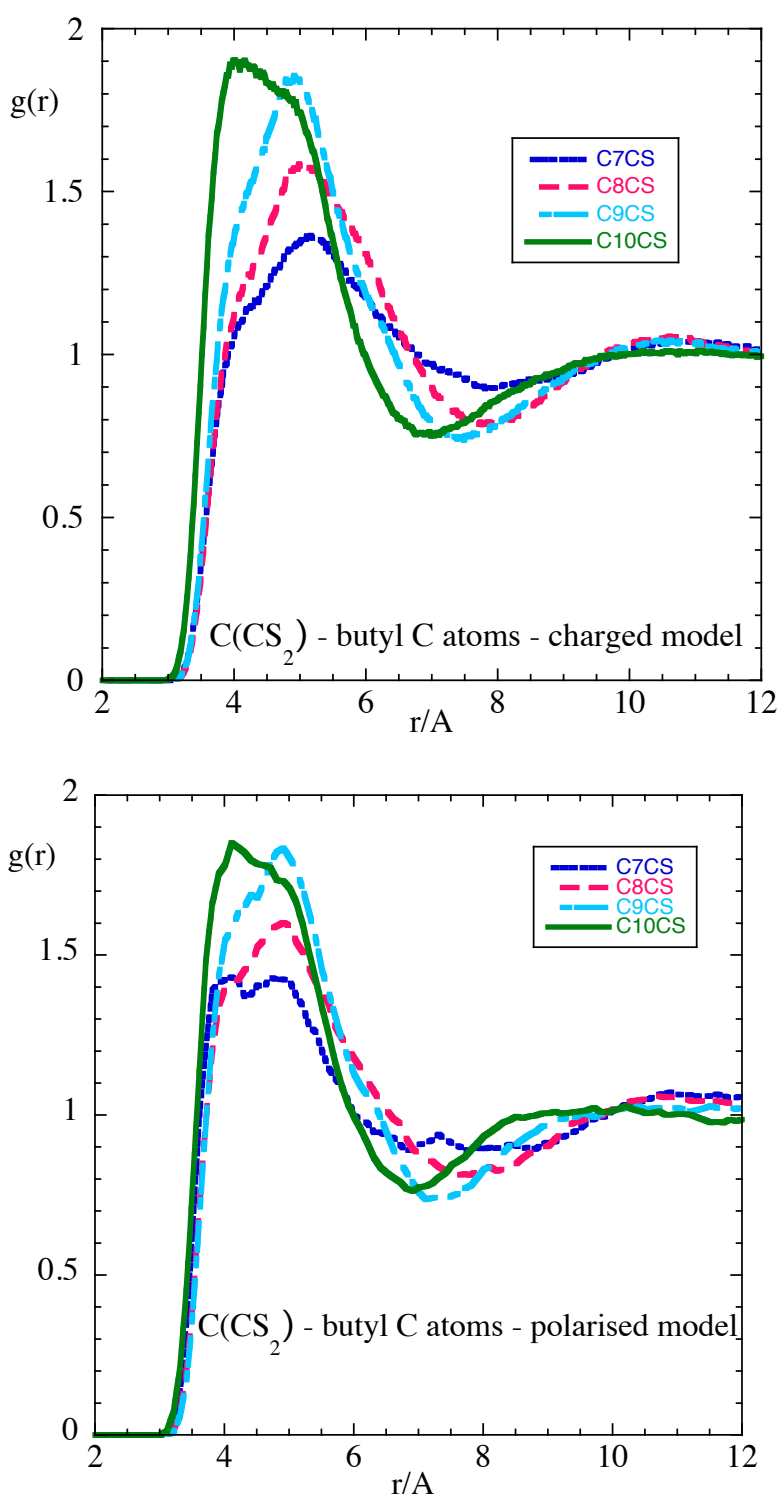

Fig. 3 Radial distribution function between the centre of $\mathrm{CS}_{2}$ and the 4 carbon atoms in the butyl side chain. $\mathrm{C} 7$ is attached to the imidazolium ring and $\mathrm{C} 10$ is the terminal carbon atom. Above:charged model; below: polarizable model. Note the preference for the tail group (C10) is decreased when polarizability is included.
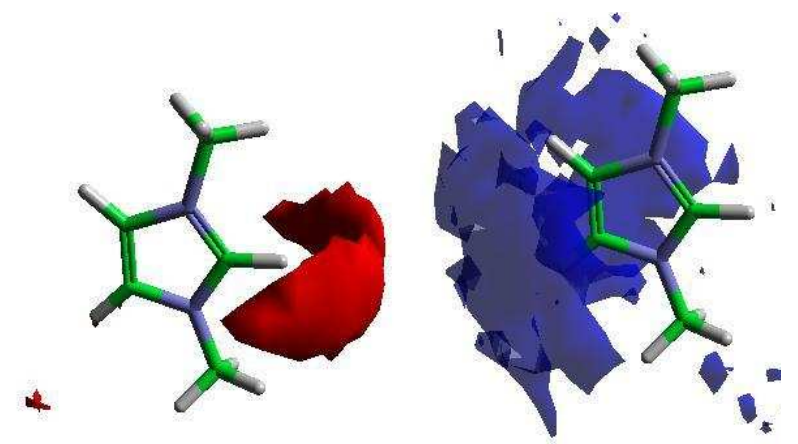

Fig. 4 Three dimensional distribution of $\mathrm{CS}_{2}$ around a $\left[\mathrm{C}_{1} \mathrm{C}_{1} \mathrm{im}\right]^{+}$ ion. Red: polarizable model, cutoff 2.5 times average number density; blue: charged unpolarizable model, cutoff 1.3 times average number density.

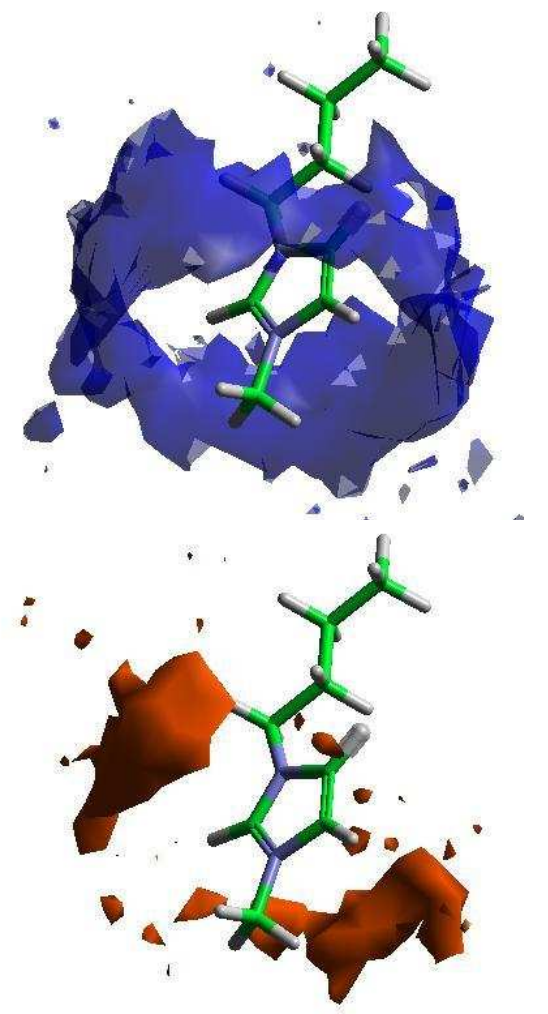

Fig. 5 Three dimensional distribution of $\mathrm{CS}_{2}$ around a $\left[\mathrm{C}_{4} \mathrm{C}_{1} \mathrm{im}\right]^{+}$ ion. Red: polarizable model, cutoff 3 times average number density; blue: charged unpolarizable model, cutoff 1.3 times average number density. 

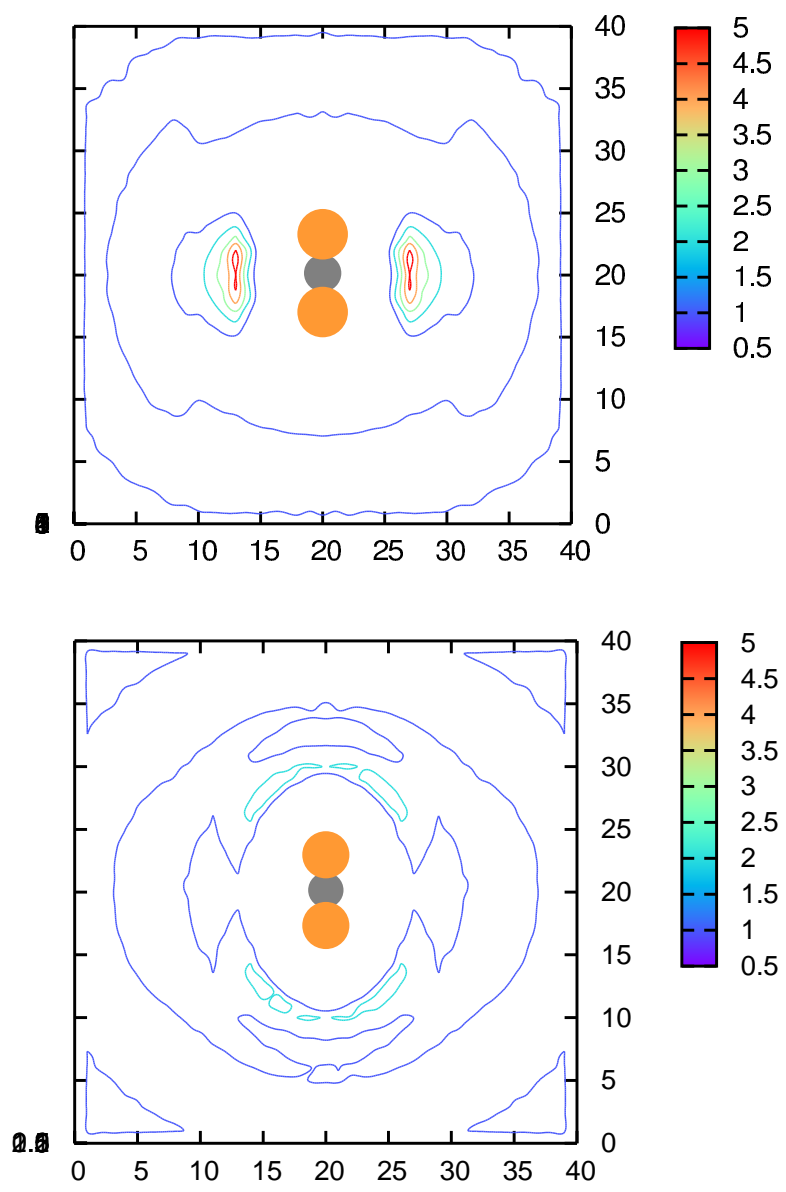

Fig. 6 Cross sections of $3 \mathrm{~d}$ distributions of ionic liquid ions around a polarizable $\mathrm{CS}_{2}$ molecule in $\left[\mathrm{C}_{1} \mathrm{C}_{1} \mathrm{im}\right]\left[\mathrm{NTf}_{2}\right]$. The contour scale is the number density relative to the bulk value. The $\mathrm{x}$ and $\mathrm{y}$ scales are in units of $0.5 \AA$. Above: concentration of ring centres; below: concentration of anion oxygen atoms.

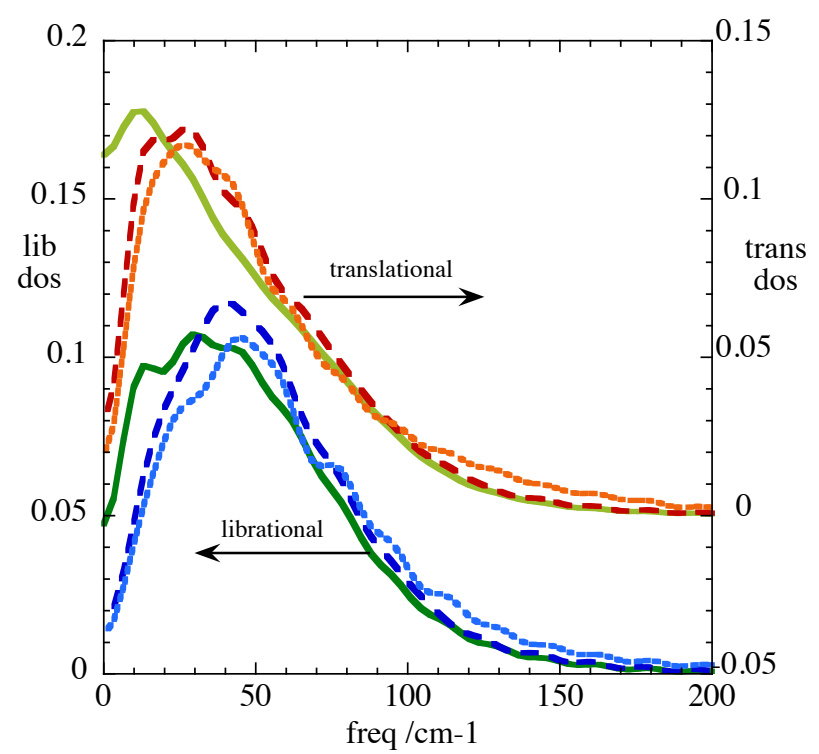

Fig. 7 Vibrational densities of states for polarisable $\mathrm{CS}_{2}$ in three environments. Solid lines: neat $\mathrm{CS}_{2}$; dashed lines $\mathrm{CS}_{2}$ in $\left[\mathrm{C}_{4} \mathrm{C}_{1} \mathrm{im}\right]\left[\mathrm{NTf}_{2}\right]$; dotted lines $\mathrm{CS}_{2}$ in $\left[\mathrm{C}_{1} \mathrm{C}_{1} \mathrm{im}\right]\left[\mathrm{NTf}_{2}\right]$. The translational contributions are displaced by 1 unit relative to the librational contributions. 


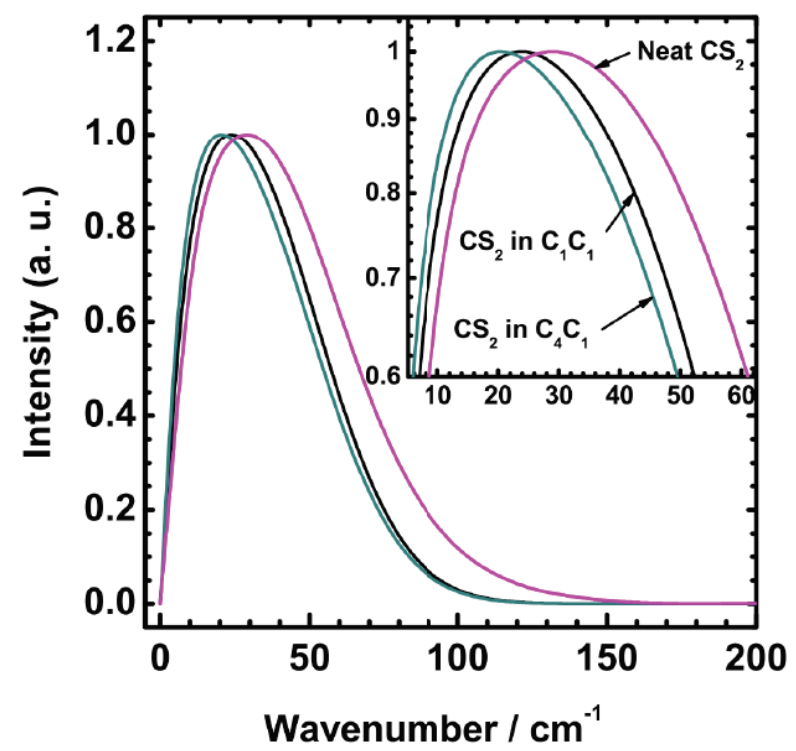

Fig. 8 Comparison of OHD-RIKES spectra of $\mathrm{CS}_{2}$ in different environments. The height-normalized reduced spectral density of $\mathrm{CS}_{2}$ from neat $\mathrm{CS}_{2}$ and the $\mathrm{CS}_{2}$ contributions to the reduced spectral densities of the $10 \mathrm{~mol} \%$ mixtures of $\mathrm{CS}_{2}$ in $\left[\mathrm{C}_{1} \mathrm{C}_{1}\right.$ im] $]\left[\mathrm{NTf}_{2}\right]$ and $\left[\mathrm{C}_{4} \mathrm{C}_{1} \mathrm{im}\right]\left[\mathrm{NTf}_{2}\right]$ are shown. Spectral parameters are given in Table 3. The inset shows an expanded view of the spectra in the region of the peak. Adapted from Figure 5 of Xue et al. ${ }^{18}$ 